Pesq. Vet. Bras. 28(5):231-236, maio 2008

\title{
Influência do exercício na indução da apoptose e necrose das células do líquido sinovial de eqüinos atletas ${ }^{1}$
}

\author{
Luciane Rasera ${ }^{2}$, Cristina O. Massoco ${ }^{3}$, Richardt G. Landgraf ${ }^{4}$ e \\ Raquel Y.A. Baccarin $2^{*}$
}

\begin{abstract}
Rasera L., Massoco C.O., Landgraf R.G. \& Baccarin R.Y.A. 2008. [Exercise induced apoptosis and necrosis in the synovial fluid cells of athletic horses.] Influência do exercício na indução da apoptose e necrose das células do líquido sinovial de eqüinos atletas. Pesquisa Veterinária Brasileira 28(5):231-236. Departamento de Clínica Médica, Faculdade de Medicina Veterinária e Zootecnia, Universidade do Estado de São Paulo, Av. Prof. Dr. Orlando Marques de Paiva 87, Butantan, São Paulo, SP 05508-270, Brazil. E-mail: baccarin@usp.br

The effects of biomechanical stress on inflammatory and adaptative responses of articular tissues in athletic horses were investigated. Synovial fluid was collected from the metacarpophalangeal joints of athletic horses before exercise and 3, 6, 24 hours after exercise, and as well as from the control group (without exercise). Apoptosis/necrosis percentage, TNF-a and PGE2 were determined by annexin V/PI assay, bioassay (L929) and ELISA, respectively. The results showed that total leukocyte count was higher in the athletic group when is compared with the control group. Three hours after the exercise was done there were increases of cellular apoptosis $(P>0.05)$ and necrosis $(P<0.05)$ percentage, PGE2 concentration $(P<0.05)$ and protein concentration $(P<0.05)$, and the TNF-a level has dropped. The athletic group showed moderate level of joint inflammation after the strenuous exercise. This articular tissue response to biomechanical insult due to the exercise, with high intensity after 3 hours after training associated with normality after 24 hours, reveals the articular adaptation to physical stress in athletic horses.
\end{abstract}

INDEX TERMS: Equine, joint, inflammation, exercise, flow cytometry.

RESUMO.- Examinaram-se os efeitos do estresse mecânico na resposta inflamatória e adaptativa dos tecidos articulares de cavalos atletas. O líquido sinovial foi colhido das articulações metacarpofalangeanas de eqüinos atletas antes, 3, 6 e 24 horas após o exercício, assim como de um grupo controle (cavalos não exercitados). A porcentagem de apoptose/necrose, o TNF-a e a PGE2 fo-

\footnotetext{
${ }^{1}$ Recebido em 19 de outubro de 2007.

Aceito para publicação em 31 de março de 2008.

${ }^{2}$ Departamento de Clínica Médica, Faculdade de Medicina Veterinária e Zootecnia, Universidade de São Paulo (USP), Av. Prof. Dr. Orlando Marques de Paiva 87, Butantan, São Paulo, SP 05508-270, Brasil. *Autor para correspondência: baccarin@usp.br

${ }^{3}$ Oncocell Biotecnologia Ltda, Alameda Ministro Rocha Azevedo 346, $1^{\circ}$ andar, Cerqueira Cezar, São Paulo, SP 01410-000.

${ }^{4}$ Instituto de Ciências Biomédicas, USP, Av. Prof. Lineu Prestes 2415, Butantan, São Paulo, SP 05508-900.
}

ram determinados pelo ensaio de AnexinaV/lodeto de Propídeo, bioensaio (L929) e ELISA, respectivamente. Os resultados mostraram que a contagem total de células nucleadas foi sempre menor no grupo controle em relação ao grupo atleta $(P<0,05)$. Observaram-se aumentos na porcentagem de células em apoptose $(P<0,05)$ e necrose $(P<0,05)$, concentração de $P G E 2(P<0,05)$ e proteína sinovial $(P<0,05)$, e diminuição da concentração de TNF-a $(\mathrm{P}<0,05)$ após 3 horas do término do exercício. $\mathrm{O}$ grupo atleta apresentou grau moderado de inflamação articular após o exercício intenso. Esta resposta dos tecidos articulares frente ao insulto mecânico do exercício, com maior intensidade às 3 horas após término da atividade esportiva e retornando à normalidade 24 horas após, revela a capacidade da adaptação articular ao estresse físico, em eqüinos atletas.

TERMOS DE INDEXAÇÃO: Eqüino, articulação, inflamação, exercício, citometria de fluxo. 


\section{INTRODUÇÃO}

Os tecidos articulares se adequam à magnitude e freqüência da força aplicada sobre eles, o que ocorre naturalmente durante o exercício. Logo, o treinamento é desejado para promover a adaptação das respostas fisiológicas e das estruturas articulares, com intuito de se manter um alto desempenho atlético com menor comprometimento articular.

Sabe-se que a carga compressiva imposta aos tecidos articulares de cavalos atletas, submetidos a treinamento diário, provoca uma resposta inflamatória com produção de fatores de crescimento, citocinas e enzimas pelas células sinoviais, que podem ser mensurados no líquido sinovial. Portanto, a regulação inadequada da resposta inflamatória após exercício pode levar a dano tecidual excessivo ou à inflamação crônica (Bertone 2004).

Alguns modelos experimentais de artrite já foram delineados para se estudar a resposta inflamatória dos tecidos articulares, sendo os principais deles a criação de uma instabilidade articular ou a injeção de agentes irritantes (May 1996), como o lipopolissacarídeo (LPS). Porém, são poucos os estudos que quantificam a resposta inflamatória e a relacionam com as alterações degenerativas articulares nos cavalos em treinamento.

Os estudos realizados para avaliar a influência das citocinas no metabolismo articular, concluíram que, principalmente, a interleucina-1 (IL-1) e o fator de necrose tumoral-alfa (TNF-a) modulam a síntese de metaloproteinases pelos condrócitos e células sinoviais, interferindo na síntese e degradação das moléculas de proteoglicanos e colágeno da matriz, e alteram o equilíbrio bioquímico necessário para a manutenção da integridade da cartilagem articular (Jouglin et al. 2000, Fernandes et al. 2002, Ottonello et al. 2002, Schuerwegh et al. 2003). Este desequilíbrio bioquímico leva a alterações degenerativas na cartilagem e, com isso, uma menor resistência às cargas compressivas impostas durante o exercício, sendo um fator predisponente para a ocorrência da osteoartrite, principalmente nos animais atletas (Chrisman et al. 1981, Van de Lest et al. 2000).

Além disso, foi verificado que a inflamação articular pode induzir a apoptose das células sinoviais por meio da ação das citocinas pró-inflamatórias, principalmente o TNF-a e o óxido nítrico (NO), fatores estes importantes na patogenia da osteoartrite em humanos e animais (Adams e Horton 1998, Aizawa et al. 2001, Salamone et al. 2001, Kim 2003). Segundo Herman et al (2005) o TNFa exerce seu efeito citotóxico via produção de radicais de oxigênio no ambiente intracelular, o qual induz a apoptose.

A prostaglandina $E_{2}\left(P E_{2}\right)$ também induz a apoptose dos condrócitos e suprimi a proliferação dos sinoviócitos na artrite reumatóide (Miwa et al. 2000). Sabe-se que nos tecidos articulares são os condrócitos e os sinoviócitos que produzem $\mathrm{PGF}_{2} \mathrm{a}$, 6-keto- $\mathrm{PGF}_{1} \mathrm{a}$, e principalmente $\mathrm{PGE}_{2}{ }^{19}$, sendo a síntese da $\mathrm{PGE}_{2}$ de maior magnitude pelo trauma e a ação de fatores biologicamente relevan- tes, como a interleucina-1b, o TNF-a (Kirker-Head et al. 2000, Martel-Pelletier et al. 2003).

$\mathrm{Na}$ artrite reumatóide em humanos, caracterizada por uma inflamação neutrofílica, a apoptose dos neutrófilos é essencial na prevenção dos danos teciduais excessivos. Isto porque estas células liberam potentes destruidores da cartilagem articular, como as serinas e as metaloproteinases, e a diminuição de sua população por conseguinte diminui a quantidade de enzimas liberadas. Ao contrário das células em necrose, os neutrófilos apoptóticos são prontamente reconhecidos pelos macrófagos e fagocitados sem estimular uma atividade pró-inflamatória das células fagocitárias (Salamone et al. 2001, Catrina et al. 2005).

A apoptose é uma forma de morte celular fisiológica onde ocorre remoção das células velhas, danificadas ou anormais, que poderiam interferir com as funções dos tecidos biológicos. A apoptose possui características distintas da morte celular patológica ou da necrose. As células apoptóticas sofrem fragmentação nuclear e brotamento citoplasmático para a formação de fragmentos celulares chamados de corpos apoptóticos, que são rapidamente fagocitados e destruídos pelos macrófagos vizinhos. A fragmentação celular não leva à liberação do conteúdo celular, e a fagocitose dos corpos apoptóticos não leva à inflamação, conseqüentemente sem danos às células adjacentes ou tecidos (Abbas et al. 2000, Tizard 2000).

A necrose é o ponto final das alterações celulares, sendo uma conseqüência comum de inflamações, processos degenerativos e infiltrativos, e de muitas alterações circulatórias. O mesmo agente etiológico pode provocar tanto necrose quanto apoptose, sendo que a severidade da agressão parece ser o fator determinante do tipo de morte celular (Abbas et al. 2000, Tizard 2000).

Existem vários ensaios para se detectar células em apoptose, como aqueles que verificam a fragmentação do DNA em tecidos (TUNEL) (Miwa et al. 2000, Kim et al. 2003), ou da externalização da fosfatidilserina (Ottonello et al. 2002, Catrina et al. 2005), medida por meio da ligação da anexina-V-FITC, utilizando a técnica de citometria de fluxo.

Ottonello et al (2002) estudaram a ação in vitro do TNFa sobre a apoptose dos neutrófilos do líquido sinovial de pacientes humanos com artrite reumatóide, e observaram que esta citocina exerceu um breve efeito pró-apoptótico nos estágios iniciais (entre 3 e 6 horas) da exposição dos neutrófilos ao TNF-a (10ng/mL) e potente ação anti-apoptótica no tempo subseqüente. Entretanto Salamone et al (2001) mostraram um grande aumento na apoptose dos neutrófilos após a exposição ao TNF-a. Portanto, ainda não foi bem definido o mecanismo que determina se o efeito dominante do TNF-a é a ativação celular ou a apoptose.

Assim sendo, a influência do TNF-a na indução da apoptose em condrócitos in vitro (Miwa et al. 2000, Aizawa et al. 2001) e a ação anti-apoptótica do TNF-a nas células sinoviais de pacientes com artrite reumatóide (Ottonello et al. 2002) foram estudadas, contudo não existem estu- 
dos mostrando a ocorrência de apoptose no líquido sinovial de animais hígidos submetidos a atividade esportiva.

O objetivo deste estudo foi quantificar a ocorrência de apoptose e de necrose das células do líquido sinovial em cavalos atletas, após exercício, correlacionando-a com a quantidade de células nucleadas totais, e as concentrações de TNF-a e PGE 2 sinovial. Com isso pretendeu-se ampliar o conhecimento sobre a influência do exercício no desencadeamento da resposta inflamatória articular.

\section{MATERIAL E MÉTODOS}

As amostras de líquido sinovial de cavalo foram colhidas em 16 articulações metacarpofalangeanas hígidas. Oito destas foram obtidas de cavalos atletas (grupo atleta), com idade entre 12 e 16 anos, machos e fêmeas, de um time de pólo de alto handicap submetidos ao mesmo esquema e ritmo de treinamento, alojados no mesmo haras na cidade de Indaiatuba, São Paulo. As oito articulações restantes formaram o grupo controle, sendo de cavalos com idade entre 10 a 12 anos, que não praticavam qualquer tipo de modalidade esportiva e não possuíam histórico ou apresentavam afecções articulares, avaliadas por exame físico e radiográfico.

A artrocentese das articulações metacarpofalangeanas foi realizada através do ligamento sesamoideano colateral lateral, segundo técnica descrita por Misheff e Stover (1991). Cada amostra de $1,0 \mathrm{~mL}$ foi acondicionada em tubos contendo EDTA para a contagem total das células nucleadas, dosagem de proteína total e a realização do ensaio de apoptose e necrose. Para a quantificação de TNF-a e PGE ${ }_{2}, 1,0 \mathrm{~mL}$ da amostra foi acondicionado em tubo esterilizado seco, centrifugado e o sobrenadante congelado em freezer $-70^{\circ}$ para posterior análise. As amostras de líquido sinovial do grupo atleta foram colhidas no dia anterior ao jogo de pólo (momento zero) e 3, 6 e 24 horas após o término do jogo, e a colheita nos animais do grupo controle foi realizada somente em um momento.

O líquido sinovial foi analisado quanto à coloração, sendo classificado como amarelo claro, amarelo ouro e vermelho; e quanto ao aspecto, como límpido, semiturvo e turvo, recebendo escores de 1 a 3 para cada característica analisada. Registrouse também o volume de líquido sinovial obtido em cada momento de colheita.

As amostras destinadas à contagem total de células nucleadas foram centrifugadas durante 10 minutos a $100 \mathrm{xg}$, sendo o sedimento ressuspendido em $1,0 \mathrm{~mL}$ de PBS (solução tampão de fosfato, $\mathrm{pH}=7,4$ ), realizando a contagem em câmara de Neubauer.

Para a dosagem de proteína total foi utilizado o sobrenadante retirado após centrifugação da amostra destinada à contagem total de células nucleadas. As dosagens da proteína total foram realizadas pelo método do biureto com a utilização do analisador bioquímico automático (Analisador bioquímico automático MAS, Liasys).

O número de células sinoviais em apoptose ou necrose foi identificado pelo ensaio de externalização da fosfatidilserina por meio da técnica de citometria de fluxo proposta por Bucchieri et al (2002). Após a contagem total de células em câmara de Neubauer, o número de células foi ajustado para uma concentração final de $1 \times 10^{5}$ células contidas em $100 \mathrm{~mL}$ de uma solução de anexina $V$ conjugada com FITC (ficoeritrina) na diluição 1:500 (Laboratório de Farmacologia, Departamento de Patologia, Faculdade de Medicina Veterinária e Zootecnia, USP,
São Paulo, SP) diluída em tampão de ligação (10mM Hepes/ $\mathrm{NaOH} ; 140 \mathrm{mM} \mathrm{NaCl} ; 2,5 \mathrm{mM} \mathrm{CaCl}_{2} ; \mathrm{pH}=7,4$ ) e iodeto de propídeo (PI, 15mg/mL; Sigma Chemicals, St Louis, USA). As células foram incubadas em tubos de propileno, protegidas da luz e mantidos a temperatura ambiente durante 15 minutos. A detecção da porcentagem de células em apoptose e necrose foi determinada em citômetro de fluxo (Becton Dickinson Immunocytometry System, San Jose, CA, USA) conectado com um computador (Macintosh Apple, CA, USA) utilizando-se o software Cell Quest iPro. As populações celulares analisadas foram reconhecidas por meio das propriedades FSC/SSC das mesmas. A fluorescência verde do FITC foi mensurada a 530 $\pm 30 \mathrm{~nm}$ (detector FL1) e a fluorescência vermelha do iodeto de propídeo foi mensurada a $585 \pm 42 \mathrm{~nm}$ (FL2).

As células coradas em verde (anexina-V-FITC) foram consideradas células apoptóticas em estado inicial (apoptose basal), aquelas coradas em vermelho (PI) foram consideradas células necróticas, as células coradas em verde e vermelho (anexina-V-FITC e PI) foram consideradas células em apoptose tardia (apoptose decorrente do exercício) e as células viáveis foram aquelas sem nenhuma marcação.

A quantificação do TNFa no líquido sinovial foi realizada através de um ensaio de citotoxicidade in vitro sobre células L929, segundo técnica descrita por Flick \& Gifford (1984). Os resultados obtidos após a leitura foram expressos em densidade óptica (DO), sendo transformados em $\mathrm{ng} / \mathrm{mL}$, mediante equação de regressão linear com base na curva padrão. Já a concentração de $\mathrm{PGE}_{2}$ do líquido sinovial foi determinada por ELISA (Cayman Chemical Co, MI, USA), de acordo com técnica descrita por Pradelles et al. (1985), Laboratório de Imunologia, Instituto de Ciências Biológicas, USP, São Paulo, SP).

Os dados foram avaliados segundo a normalidade pelo teste de Kolmojorov-Smirnov; em seguida o modelo de análise de variância para verificar o efeito de grupos foi utilizado. 0 contraste entre médias foi feito pela d.m.s. do teste de Tukey a nível de $5 \%$ de probabilidade. Para os dados não paramétricos utilizou-se o teste Kruskal-Wallis.

\section{RESULTADOS}

$O$ volume de líquido sinovial $(\mathrm{mL})$ obtido às 3 e 6 horas diminuiu $(P<0,05)$ em relação ao momento zero e às 24 horas. Comparativamente ao grupo controle houve diferença significativa em relação aos momentos zero, 6 e 24 horas (Quadro1). A coloração do líquido sinovial tornou-se avermelhada às 3 e 6 , e amarelo ouro às 24 horas diferindo $(P<0,05)$ da coloração amarelo palha do momento zero e do grupo controle. Não houve alteração no aspecto do líquido sinovial $(P>0,05)$, apresentando-se límpido em todos os momentos analisados, em ambos os grupos.

Todos os valores médios da concentração de proteína total $(\mathrm{g} / \mathrm{dL})$ no líquido sinovial das articulações metacarpofalangeanas do grupo atleta, ou seja, momento zero, 3, 6 e 24 horas após o término do jogo foram maiores $(P<0,05)$ do que os valores do grupo controle. Também ocorreu aumento significativo de proteína total 6 e 24 horas após término do jogo em relação ao momento zero no grupo atleta (Quadro1).

O número de células nucleadas do líquido sinovial do grupo controle (céls $/ \mathrm{mL})$ foi menor $(P<0,05)$ do que nos momentos zero, 3, 6 e 24 horas do grupo atleta. Não foi 


\begin{tabular}{|c|c|c|c|c|c|}
\hline & Controle & Mo & 3 horas & 6 horas & 24 horas \\
\hline Volume (mL) & $1,68^{\mathrm{C}} \pm 0,45$ & $5,41^{a} \pm 1,92$ & $2,98^{b c} \pm 1,62$ & $3,09^{b} \pm 1,81$ & $6,25^{\mathrm{b}} \pm 1,75$ \\
\hline Proteína total (g/dL) & $0,50^{a} \pm 0,23$ & $1,10^{\mathrm{b}} \pm 0,44$ & $1,62^{b c} \pm 0,38$ & $1,78^{\mathrm{C}} \pm 0,50$ & $1,89^{c} \pm 0,52$ \\
\hline Células nucleadas (céls/mL) & $25^{\mathrm{a}} \pm 11,95$ & $130^{\mathrm{b}} \pm 79,28$ & $165^{\mathrm{b}} \pm 132,02$ & $127,78^{b} \pm 94,25$ & $157,50^{\mathrm{b}} \pm 96,02$ \\
\hline $\mathrm{PGE}_{2}(\mathrm{pg} / \mathrm{mL})$ & $34,60^{a_{ \pm}} 31,57$ & $116,10^{b} \pm 48,69$ & $521,75^{c} \pm 331$ & $476,48^{\mathrm{C}} \pm 307,10$ & $182,72^{\mathrm{b}} \pm 91,88$ \\
\hline TNF-á (pg/mL) & $185,0^{a}$ & $768,5^{\mathrm{b}}$ & $326,0^{a b}$ & $750,0^{a b}$ & $755,0^{\mathrm{b}}$ \\
\hline
\end{tabular}

Para letras diferentes médias estatisticamente significativas $(P<0,05)$.

Quadro 2. Mediana da porcentagem de células em apoptose total, apoptose inicial, apoptose tardia e necrose, média e desvio-padrão da porcentagem de células viáveis no líquido sinovial das articulações metacarpofalangeanas de cavalos atletas, antes (M0), 3, 6, e 24 após o término do jogo, e dos animais do grupo controle. São Paulo, 2007

\begin{tabular}{cccccc}
\hline & $\begin{array}{c}\text { Apoptose } \\
\text { total } \\
\text { (\% céls) }\end{array}$ & $\begin{array}{c}\text { Apoptose } \\
\text { inicial } \\
\text { (\% céls) }\end{array}$ & $\begin{array}{c}\text { Apoptose } \\
\text { tardia } \\
\text { (\% céls) }\end{array}$ & $\begin{array}{c}\text { Necrose } \\
\text { (\% cels) }\end{array}$ & $\begin{array}{c}\text { Células } \\
\text { viáveis } \\
\text { (\% cels) }\end{array}$ \\
\hline Controle & $0,30^{\mathrm{c}}$ & $0,23^{\mathrm{b}}$ & $0,06^{\mathrm{c}}$ & $0,52^{\mathrm{c}}$ & $98,78 \pm 0,75^{\mathrm{a}}$ \\
M0 & $4,01^{\mathrm{ab}}$ & $1,74^{\mathrm{a}}$ & $2,27^{\mathrm{ab}}$ & $2,63^{\mathrm{b}}$ & $86,89 \pm 11,08^{\mathrm{b}}$ \\
3 horas & $7,97^{\mathrm{b}}$ & $0,20^{\mathrm{b}}$ & $7,58^{\mathrm{b}}$ & $20,76^{\mathrm{a}}$ & $66,22 \pm 22,18^{\mathrm{b}}$ \\
6 horas & $4,27^{\mathrm{ab}}$ & $0,56^{\mathrm{b}}$ & $3,20^{\mathrm{ab}}$ & $3,15^{\mathrm{b}}$ & $92,01 \pm 3,08^{\mathrm{b}}$ \\
24 horas & $0,75^{\mathrm{ac}}$ & $0,23^{\mathrm{b}}$ & $0,46^{\mathrm{ac}}$ & $2,27^{\mathrm{b}}$ & $89,61 \pm 11,23^{\mathrm{b}}$ \\
\hline
\end{tabular}

Para letras diferentes, na mesma coluna, médias estatisticamente significativas $(P<0,05)$.

observada diferença $(P>0,05)$ no número de células nucleadas entre os momentos analisados do grupo atleta (Quadro 1).

Em relação à porcentagem de células em apoptose inicial, notou-se diminuição significativa $(P<0,05)$ às 3 horas em relação ao momento zero, não havendo diferença estatisticamente significante em relação aos outros momentos analisados ou ao grupo controle. Analisandose a porcentagem de células em apoptose tardia observou-se aumento significativo às 3 e 6 horas em relação às 24 horas e ao grupo controle. Também foi notado que a porcentagem de células em apoptose tardia era evidentemente maior $(\mathrm{P}<0,05)$ no momento zero do grupo atleta do que no grupo controle. Os dados referentes à apoptose tardia refletiram na porcentagem de apoptose total, ou seja, houve aumento significativo às 3 e 6 horas em relação às 24 horas e ao grupo controle, e diferença significativa $(P<0,05)$ entre o momento zero do grupo atleta e o grupo controle (Quadro 2)

A porcentagem de células em necrose às 3 horas em relação ao momento zero, 6 e 24 horas teve aumento significativo. Houve diferença significativa na porcentagem de células em necrose entre o grupo controle e os momentos zero, 3, 6 e $24 \mathrm{~h}$ do grupo atleta. Analisando a porcentagem de células viáveis no líquido sinovial observou-se diferença $(P<0,05)$ entre o grupo controle e todos os momentos do grupo atleta (Quadro 2).
A concentração de TNF-a $(\mathrm{pg} / \mathrm{mL})$ do líquido sinovial do grupo controle mostrou-se menor do que as do momento zero e 24 horas do grupo atleta $(P<0,05)$, porém similar aos momentos 3 e 6 do grupo atleta $(P>0,05)$ (Quadro 1, Fig.1).

Os níveis de $\mathrm{PGE}_{2}(\mathrm{pg} / \mathrm{mL})$ no líquido sinovial do gru-

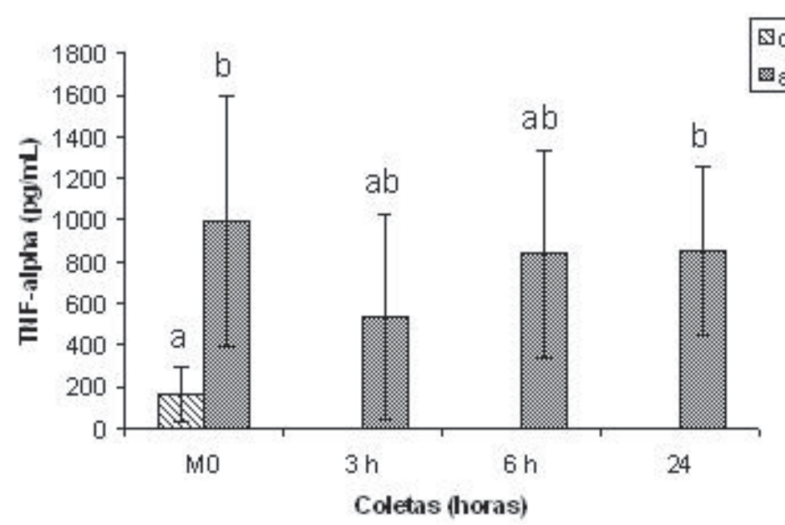

Fig.1. Valores médios da concentração de TNFa $(\mathrm{pg} / \mathrm{mL})$ no líquido sinovial das articulações metacarpofalangenas dos cavalos atletas, antes (M0) e 3, 6, e 24 horas após o término do jogo, e dos animais do grupo controle. São Paulo, 2007.

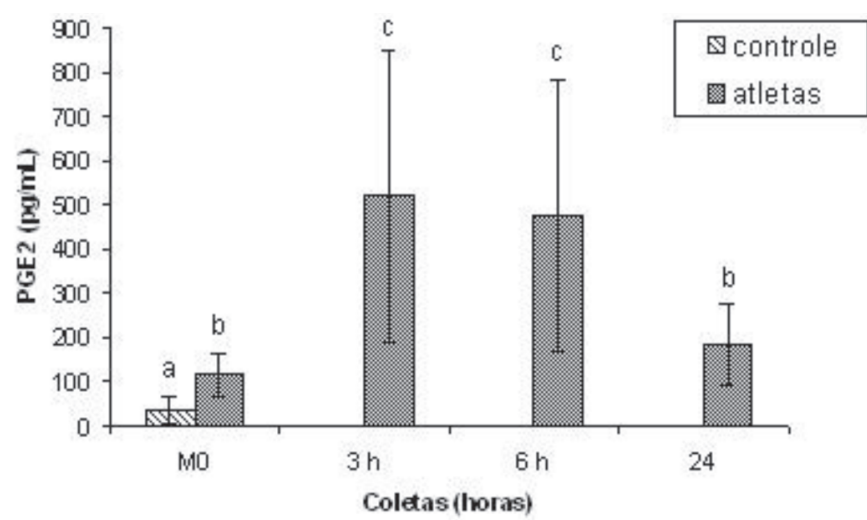

Fig.2. Valores médios da concentração de $P G E_{2}(\mathrm{pg} / \mathrm{mL})$ no líquido sinovial das articulações metacarpofalangenas dos cavalos atletas, antes (M0) e 3, 6, e 24 horas após o término do jogo, e dos animais do grupo controle. São Paulo, 2007. 
po atleta às 3 e às 6 horas após o exercício em relação ao momento zero e 24 horas teve aumento significativo. Houve diferença significativa entre o grupo controle e todos os momentos do grupo atleta (Quadro 1, Fig.2).

\section{DISCUSSÃO E CONCLUSÃO}

O movimento articular durante o exercício é o maior agente ativador da circulação sinovial, modificando a pressão intra-articular e o fluxo sangüíneo sinovial. Também o deslocamento de líquido através da membrana sinovial para o interstício e vasos linfáticos aumenta durante o exercício, melhorando a rotatividade do líquido articular (Levick 1987). Portanto, a diminuição no volume obtido de líquido sinovial das articulações metacarpofalangeanas do grupo atleta, após 3 horas do término do exercício, pode ser conseqüência do aumento desta rotatividade sinovial, apesar do aumento no fluxo sangüíneo e conseqüente aumento na produção de líquido sinovial que ocorre durante a movimentação articular. Levick (1987) também citou diminuição no volume de líquido sinovial após o exercício em humanos, porém não identificou o momento de colheita. Fato importante foi que o volume de líquido sinovial do grupo atleta apresentou-se maior que os valores do grupo controle em todos os momentos, demonstrando a influência do exercício no volume de líquido sinovial das articulações metacarpofalangeanas de cavalos atletas.

Sabe-se também que o exercício, ou seja, o vigoroso movimento sinovial, aumenta a permeabilidade da barreira sangüínea-articular a macromoléculas e partículas (Levick 1987). Logo, a alteração na coloração do líquido articular obtido das articulações dos animais atletas após o término do exercício, deve ser decorrente da hiperemia da membrana sinovial, ocasionada pelo aumento do fluxo sangüíneo, associada ao aumento da permeabilidade sangüínea-articular.

O aumento da permeabilidade capilar à macromoléculas e a maior dinâmica do líquido articular decorrentes do exercício (Levick 1987) mantêm um maior influxo das células inflamatórias e de proteína para a cavidade articular, o que pôde ser observado pela maior número destas células e de concentração protéica no líquido sinovial do grupo atleta em relação ao grupo controle. Porém, a contagem de células nucleadas não aumentou no decorrer das 24 horas analisadas após o exercício. Estes resultados podem ser interpretados como uma reação inflamatória constante, decorrente do insulto repetitivo do exercício à membrana sinovial.

Sob condições fisiológicas a apoptose ocorre como uma renovação das células dos tecidos biológicos, tendo, portanto um valor basal de ocorrência (Tizard 2000). Com o aumento das exigências teciduais sob comando do exercício, a porcentagem de células em apoptose provavelmente seja maior, como observado neste estudo (apoptose tardia). Porém, o exercício intenso também provocou morte celular por necrose das células inflamatórias e sinoviais, principalmente 3 horas após seu término, com conseqüente liberação de mediadores inflamatórios, como a PGE . .

Juntamente com o aumento na porcentagem de apoptose e necrose celulares após 3 horas do término do exercício houve diminuição na concentração de TNF-a no líquido sinovial. Este fato pode indicar uma ação antiapoptótica do TNF-a, e corroborar com os achados de Catrina et al (2005) que verificaram aumento na apoptose dos macrófagos do líquido sinovial de pacientes com artrite reumatóide após tratamento com anticorpo anti-TNFa. Porém, contraria os achados de Ottonello et al (2002) que verificaram um efeito pró-apoptótico nas células do líquido sinovial nas primeiras horas de exposição ao TNFa, com subseqüente ação anti-apoptótica sob estas células. Também poderia ser explicada pela ligação do TNFaos seus receptores de membrana localizados nas células inflamatórias e sinoviais. A ligação com o receptor de membrana do tipo I (TNFRI) com domínio citoplasmático para a morte celular (TRADD) ativa a apoptose celular, mas a ligação com o receptor de membrana do tipo II (TNFRII) ativa os fatores de transcrição nas células alvo (NF-kB e AP-1) com produção dos mediadores inflamatórios, como as prostaglandinas (Abbas et al. 2000). Deve ser lembrado que após 3 horas do término do exercício observou-se marcante aumento na concentração de $\mathrm{PGE}_{2}$ no líquido sinovial dos animais atletas, cujo estímulo pode ter sido causado pela ligação do TNF-a com o TNFRII, levando a necrose celular.

A concentração de $P G E_{2}$ no grupo atleta às $3(521,75 p g /$ $\mathrm{mL}$ ) e $6(476,48 \mathrm{pg} / \mathrm{mL})$ horas manteve-se próximo aos valores encontrados por Kirker-Head et al (2000) em animais com osteoartrite $(361,60 \mathrm{pg} / \mathrm{mL})$, muito acima do que eles consideraram como líquido sinovial sadio $(5,7 \mathrm{pg} / \mathrm{mL})$. Esta semelhança na concentração de $\mathrm{PGE}_{2}$ evidencia o efeito do estresse físico nos tecidos articulares, com aumento do estímulo para a produção dos mediadores inflamatórios. Além disso, o aumento na concentração da $\mathrm{PGE}_{2}$ após 3 horas do exercício com concomitante aumento na porcentagem das células em apoptose no grupo atleta, corrobora com os achados encontrados por Miwa et al (2000), indicando um efeito pró-apoptótico da $\mathrm{PGE}_{2}$. Bertone (2004) relata que todos os eqüinos com carreira atlética longa terão um certo grau de osteoartrite.

Os resultados apresentados mostram algumas alterações bioquímicas ocorridas no líquido sinovial de cavalos atletas, evidenciando uma resposta inflamatória dos tecidos articulares frente ao trauma do exercício. Devido à ausência de sinais clínicos de doença articular em todos os animais utilizados neste estudo, concluiu-se que as articulações dos cavalos atletas, que são submetidas ao exercício físico intenso, passam por um processo inflamatório e adaptativo na tentativa de suprir as necessidades fisiológicas do treinamento esportivo.

\section{REFERÊNCIAS}

Abbas A.K. Lichtman A.H. \& Pober S.J. 2000. Cellular and molecular immunology. 4th ed. Saunders Company, Philadelphia. 553p. 
Adams C.S. \& Horton W.E. 1998. Chondrocyte apoptosis increases with age in the articular cartilage of adult animals. Anat. Rec. 250(4):418425.

Aizawa T., Kon T., Einhorn T.A. \& Gerstenfeld L.C. 2001. Induction of apoptosis in choncrocytes by tumor necrosis factor-alpha. J. Orth. Res. 19(5):785-796.

Bertone A.L. 2004. Joint physiology: responses to exercise and training, p.152-160. In: Hinchcliff K.W., Kaneps A.J. \& Geor R.J. (ed.), Equine Sports Medicine and Surgery: Basic and clinical sciences of the equine athlete. Saunders, China.

Bucchieri F., Pubbicomb S.M., Lordan J.L., Richter A., Buchanan A., Wilson S.J., Ward J., Zummo G., Howarth P.H., Djukanoviæ R., Holgate S.T. \& Davies D.E. 2002. Asthmatic bronchial epithelium is more susceptible to oxidant-induced apoptosis. Am. J. Resp. Cell Mol. Biol. 27(2):179-185.

Catrina A.I., Trollmo C., Klint E., Engstrom M., Lampa J., Hermansson Y., Klareskog L. \& Ulfgren A.K. 2005. Evidence that anti-tumor necrosis factor therapy with both etanercept and inflimab induces apoptosis in macrophages, but not lymphocytes; in rheumatoid arthritis joints. Arth. Rheum. 52(1):61-72.

Chrisman O.D., Ladenbauer-Bellis J.M., Panjabi M. \& Goeltz S. 1981. The relationship of mechanical trauma and the early biochemical reactions of osteoarthritic cartilage. Clin. Orth. 161:275-84.

Fernandes J.C., Martel-Pelletier J. \& Pelletier J.P. 2002. The role of cytokines in osteoarthritis pathophysiology. Biorheology 39(1-2):237246.

Flick D.A. \& Gifford G.E. 1984. Compararison of in vitro cell cytotoxic assays for tumor necrosis factor. J. Immun. Meth. 68(1-2):167-175.

Herman S., Zurgil N. \& Deutsch M. 2005. Low dose methotrexate induces apoptosis with reactive oxygen species involvement in $\mathrm{T}$ lymphocytic cell lines to a greater extent than in monocytic lines. Inflam. Res. 54(7):273-280.

Jouglin M., Robert C., Valette J.-P., Gavard F., Quintin-Colonna F. \& Denoix J.-M. 2000. Metalloproteinases and tumor necrosis factor-alpha activities in synovial fluid of horses: correlation with articular cartilage alterations. Vet. Res. 31(5):507-515.

Kim D.Y., Taylor H.W., Moore R.M., Paulsen D.B. \& Cho D-Y. 2003. Articular chondrocyte apoptosis in equine osteoarthritis. Vet. J. 166(1):52-57.
Kirker-Head C.A., Chandna V.K., Agarwal R.K., Morris E.A., Tidwell A., O'Callaghan M.W., Rand W. \& Kumar M.S.A. 2000. Concentrations of substance $P$ and prostaglandin $E_{2}$ in synovial fluid of normal and abnormal joints of horses. Am. J. Vet. Res. 61(6):714-718.

Levick J.R. 1987. Synovial fluid and trans-synovial flow in stationary and moving normal joints, p.149-186. In: Helminen H.J., Kiviranta I., Tammi M., Säämänem A-M., Paukkonen K. \& Jurvelin J. (ed.), Joint loading - biology and health of articular structures. Wright, Bristol.

Martel-Pelletier J., Pelletier J-P. \& Fahmi H. 2003. Cyclooxygenase-2 and prostaglandins in articular tissues. Sem. Arth. Rheum. 33(3):155167.

May S.A. 1996. Animals models and other experimental systems in the investigation of equine arthritis, p.421-440. In: Mcllwraith C.W. \& Trotter G.W. (ed.), Joint Disease in the Horse. W.B. Saunders, Philadelphia.

Miwa M., Saura R., Hirata S., Hayashi Y., Mizuno K. \& Itoh H. 2000. Induction of apoptosis in bovine articular chondrocyte by prostaglandin $\mathrm{E}(2)$ through cAMP-dependent pathway. Osteoarthr. Cartil. 8(1):1724.

Misheff M.M. \& Stover S.M. 1991. A comparison of two techniques for arthrocentesis of the equine metacarpophalangeal joint. Eq. Vet. J. 23(4):273-276.

Ottonello L., Cutolo M., Frumento G., Arduino N., Bertolotto M., Manzini M., Sottofattori E. \& Dallegri F. 2002. Synovial fluid from patients with rheumatoid arthritis inhibitis neutrophil apoptosis: role of adenosine and proinflammatory cytokines. Rheum. 41(11):1249-1260.

Pradelles P., Grassi J. \& Maclouf J. 1985. Enzyme immunoassays of eicosanoids using acetylcholine esterase as label: an alternative to radioimmunoassay. Anal. Chem. 57(7):1170-1173.

Salamone G., Giordano M., Trevani A.S., Gamberale R., Vermeulen M., Schettinni J. \& Geffner J.R. 2001. Promotion of neutrophil apoptosis by TNF-a. J. Immunol. 166(5):3479-3483.

Schuerwegh A.J., Dombrecht E.J., Stevens W.J., Van Offel J.F., Bridts C.H. \& De Clerck L.S. 2003. Influence of pro-inflammatory (IL-1a, IL6 , TNF-a, IFN-g) and anti-inflammatory (IL-4) cytokines on chondrocyte function. Osteoarthr. Cartil. 11(9):681-687.

Tizard I.R. 2000. Imunologia Veterinária. 6ª ed. Roca, São Paulo. 532p.

Van de Lest C.H.A., Van de Hoogen B.M. \& Van Weeren P.R. 2000. Loading-induced changes in synovial fluid affect cartilage metabolism. Biorheology 37(1-2):45-55. 